\title{
Climate change impact: Food production and local Perception
}

\author{
Abu Reza Md. Towfiqul Islam ${ }^{1}$, Anjum Tasnuva ${ }^{1}$, Soniya Sultana ${ }^{2}$, Shifat Rumana $^{3}$ \\ ${ }^{1}$ Dept. of Disaster Management, Begum Rokeya University, Rangpur-5400, Bangladesh \\ ${ }^{2}$ Instructor, Environmental technology, Chittagong polytechnic Institute, Chittagong-4200, Bangladesh \\ ${ }^{3}$ Dept. of Geography and Environmental Science, Begum Rokeya University, Rangpur-5400, Bangladesh
}

Email address:

gm_towfique_06@yahoo.com (Islam, A. R. M. T.)

\section{To cite this article:}

Abu Reza Md. Towfiqul Islam, Anjum Tasnuva, Soniya Sultana, Shifat Rumana. Climate Change Impact: Food Production and Local Perception. American Journal of Environmental Protection. Vol. 3, No. 2, 2014, pp. 45-50. doi: 10.11648/j.ajep.20140302.11

\begin{abstract}
The study was carried out based on local perception of climate change impact and its consequences on food production in Koyra upazila of Khulna district in south-western Bangladesh. A questionnaire survey was conducted where 150 respondents were randomly selected to get local perception at small scale in the study area. The result revealed from people perception that increase in temperature, erratic rainfall, increase in frequency of disaster and decrease in food production which direct impact of food security in the study area. The present study was also revealed that higher knowledge variability was presented between climate change and food production for group four and group five. Correlation coefficient analysis was also indicated that significantly negatively correlated between climate change and food production for people belong to group one, two and three. Climate change impact on the agricultural production indicates threat to food security in the marginal level respondents. Most of the respondents were aware of climate change and its impact on food production but do not know how to adapt these changes. It can be concluded that socio-economic profile and people awareness regarding food production have to be tailored to cope with climate change impact.
\end{abstract}

Keywords: Local Perception, Climate Change, Food Production, Koyra Upazila, Food Security

\section{Introduction}

Bangladesh is recognized worldwide as one of the country's most vulnerable to the impact of climate change and climatic variability. Bangladesh is facing the early impacts of climate change particularly in agricultural sector [1]. The relationship between climate change and agriculture is a vital issue for food production. Food production is directly related to climate change because any variability in climatic factor can directly affect a country's ability to feed its people [2]. It affects all the components of food security [3]. Climate change affects indirectly via its impact on economic growth, income distribution and agricultural demand [4]. Fahim et al., [5] investigate that climate change will affect all four dimensions of food security, namely food production, access to food, stability of food supplies and food utilization. There is no doubt that its agriculture will be badly affected by the climate change. The national gap of the food production and the export of the food items and amount are also included here [6]. Food security depends on more socio-economic conditions than on agro climatic zones and on access to food rather than the production or physical availability of food [7]. But the natural calamities, cyclones and storm surges are totally hindering the production of various crops more and limiting the food security in the country, especially the coastal areas. Climate variability, agriculture productivity, food security, undernourished and poverty, these all are directly linked to each other; and these are strongly correlated to each other [8]. Overall impact of climate change on agricultural production will be negatively affecting in Bangladesh [9]. Studies show that without adaptation, climate change is generally problematic for agricultural production and for agricultural economies and communities [10]. Adaptation is a key factor that will shape the future severity of climate change impacts on food production [11]. Increase in diseases and pests in crops have caused decline of crop productions and threatened to food security in Bangladesh. Impact of climate change may be reduction in agricultural production and employment opportunities of population resulting it would be serious 
threat for hunger, food insecurity, poverty and malnutrition in any region [12]. Climate change imposes an indirect threat mostly in agricultural production and food security among the other affected area. The main objective of this study is to identify local perception about climate change and to explore climate change impact on food production and it consequences threat to food security in future.

\section{Materials and Method}

\subsection{Description of Study Area}

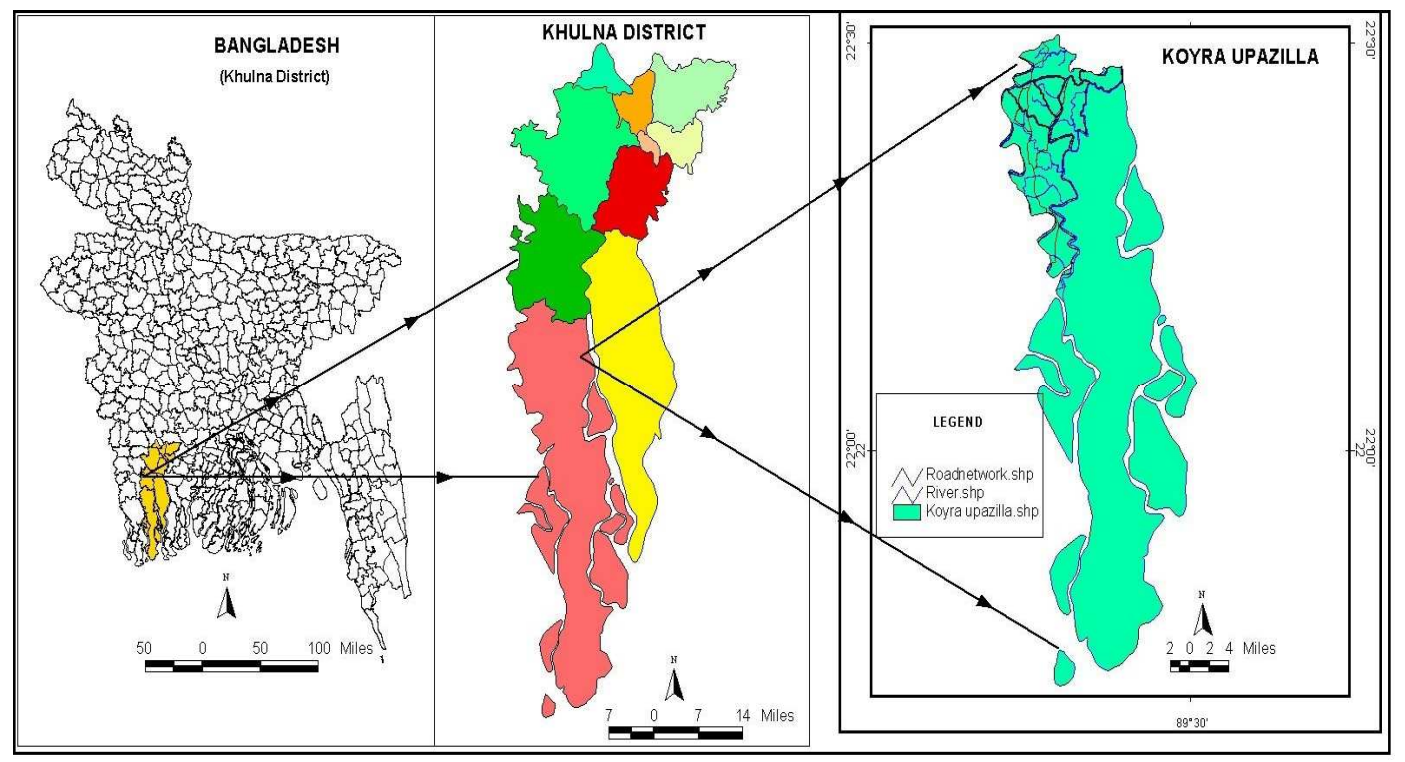

Fig 1. Location map of the study area (Amadi union, Koyra, Khulna district)

\subsection{Justification for Selection of the Study Area}

The study area is closed to the coastal region of Bangladesh and vicinity to the Bay of Bengal. It is assumed that people of the coastal area will be adversely affected due to climate change impact. Most of the people in the area are engaged in agricultural sector. Agriculture section has more vulnerable as the consequences of climate change which create a negative impact on their livelihood. Koyra is one of the upazila in Khulna district which is located very near to world heritage Sundorban region. Climate change is raised a negative impact on farmer livelihood because it reduces their food production and potential income level.

\subsection{Study Design}

The study was qualitative in nature (questionnaire survey, focus group discussions and face to face interviews) which used to identify the impacts of climate change on food production in the study area. A set of questionnaire was developed where total respondents were split into five groups to perform the aim and objective of the study. According to income level of respondent, per capita income (annual) was US \$100- US\$ 150 for group one, US \$160US \$ 210 for group two, US \$ 220- US \$ 270 for group three, US \$ 280- US \$ 330 for group four and US \$ 340- US \$ 390
The study area is situated in the south-western coastal belt of Koyra upazila of Khulna district; Bangladesh. The upazila occupies an area of $1775.41 \mathrm{sq}$. km. including $951.66 \mathrm{sq} . \mathrm{km}$ Sundarbans forest area. The main populated area of Koyra is about $263 \mathrm{sq}$. $\mathrm{km}$. The study area is located between $22^{\circ} 12$ and $22^{\circ} 31^{\prime}$ North latitudes and between $89^{\circ} 15^{\prime}$ and $89^{\circ} 26^{\prime}$ East longitudes (Fig.1). It is bounded on the north by Paikgachha upazila, on the east by Dacope upazila and the Sundarbans, on the south by the Sundarbans and the Bay of Bengal and on the west by Assasuni and Shyamnagar upazila of Satkhira district [13]. 
correlation coefficient analysis. Sigma plot software (version 7) was used to obtain knowledge variability for assessing climate change impact and food production with education level.

\section{Results}

\subsection{Socio-Economic Profile}

Socio-economic information was gathered from five different age groups. Most of the people were educated $(72 \%)$ whereas $28 \%$ respondent was illiterate in the study area. Here, education levels of the respondents fall within G-2, G-3 and G-4 respectively. On the other hand, socio-economic condition was below the poverty level. $50 \%$ respondent among total respondent were engaged in agricultural activity whereas $25 \%$ respondent was day labor (Table 1). Income levels of the most of household were belonging to group one and two in the study area people.

Table 1. Demographic information of the study area.

\begin{tabular}{|c|c|c|}
\hline S.No. & Socio-economic information & Percentage (\%) \\
\hline \multicolumn{3}{|c|}{ Age Group } \\
\hline i) & $20-30$ & 10 \\
\hline ii) & $31-40$ & 32 \\
\hline iii) & $41-50$ & 28 \\
\hline iv) & $51-60$ & 20 \\
\hline v) & Above 60 & 10 \\
\hline \multicolumn{3}{|c|}{ Educational qualification } \\
\hline G-1 & Illiterate & 28 \\
\hline G-2 & Primary level & 40 \\
\hline G-3 & Secondary level & 20 \\
\hline G-4 & Higher secondary level & 10 \\
\hline G-5 & Tertiary level & 2 \\
\hline \multicolumn{3}{|c|}{ Occupation status } \\
\hline i) & Farmer & 50 \\
\hline ii) & Businessman & 8 \\
\hline iii) & Job holder & 12 \\
\hline iv) & Day labor & 25 \\
\hline v) & Others & 5 \\
\hline
\end{tabular}

(Source: Field Survey, 2013)

\subsection{Perceived Knowledge on Climate Change Impact}

In order to understand how human beings would respond to climate change, it is essential to study people perceptions of climate and the environment in general [16]. The respondents were asked specifically if they have noticed any changes in the weather pattern in the coastal area over the past years. People have perceived knowledge on climate change effects are presented in table 2 . Here, $85 \%$ of respondents were believed that temperature was increased in the study area. By contrast none believed that the temperature was decreased. However, $70 \%$ of respondents believed that irregular rainfall was increased. Majority respondents $(75 \%)$ also believed that the occurrence of storm surges, flooding and disasters have increased. Other noticeable changes by respondents include increased uncertainty in predicting the weather, increase in erosion, and sea level rise such as waves, tides and currents.

Table 2. Perceived knowledge on climate changes as observed by respondents.

\begin{tabular}{clc}
\hline S.No. & Perceived knowledge change & Percentage (\%) \\
\hline i) & Increased in temperature & $85 \%$ \\
ii) & Drought frequency has increase & $40 \%$ \\
iii) & Erratic rainfall has increase & $70 \%$ \\
iv) & Climate is getting warmer & $70 \%$ \\
v) & Uncertainty in predicting weather & $20 \%$ \\
vi) & Variations in year-to-year weather pattern & $50 \%$ \\
vii) & Increase in storm surges, flooding and & $75 \%$ \\
viii) & disasters & More erosion \\
ix) & More changes in sea level (Waves, Tides & $65 \%$ \\
x) & \& currents) & $20 \%$ \\
\hline
\end{tabular}

(Source: Field Survey, 2013)

\subsection{Perceptive Assessment of Climate Change}

From the local perception, $40 \%$ and $30 \%$ respondents are strongly agreed to increase the deforestation and sea water intrusion whereas $35 \%, 30 \%, 25 \%$ and $35 \%$ respondents are agreed that climate change has increased the risk of crop failure, pest and disease, erosion and dry up water resource in the local community. On the other hand, $35 \%$ and $30 \%$ and $25 \%$ respondents are strongly disagreed that climate change has increased the frequency of rainfall; rainfall support crop and food grain production whereas $20 \%$ respondent is disagreed that climate change has improved the health status of the study area people. Nevertheless, $35 \%$ and $30 \%$ respondents do not know that climate change has either increased or decreased the flood and sea level rise and fresh water availability in that area (Fig. 2).

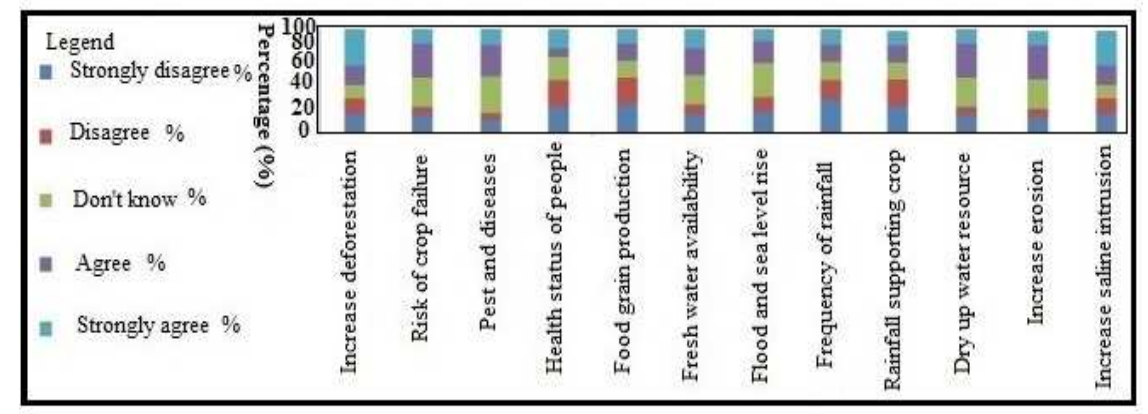

Fig 2. Local perception and climate change impact. 


\subsection{Effect of Climate Change and Food Production}

The study area people are vulnerable due to climate change effect on agriculture activities. There were various climatic changes that affect the overall agricultural sector of the selected area. These are key issues for the low lying coastal area. Normal crop $(65 \%)$ has been affected climate change by decrease in food production and affected crop like paddy and wheat etc in the study area. But majority of respondents had perceived that saline tolerance crop has increased food production (70\%) due to climate change. $90 \%$ and $80 \%$ of the respondent have perceived that uses of fertilizer and pesticides in crop are increased due to climate change. Also $85 \%$ respondents revealed that improved in irrigation technology used in the study area while other minor respondents perceived that no change and do not know on agricultural activity (Fig. 3). Local respondents revealed that food production was decreased during last 15 year and especially over the past five years (Fig. 4). When the survey took place, more than $80 \%$ of respondent were experienced low production in crop with respect to $5 \%$ and $10 \%$ and last five years ago respectively.

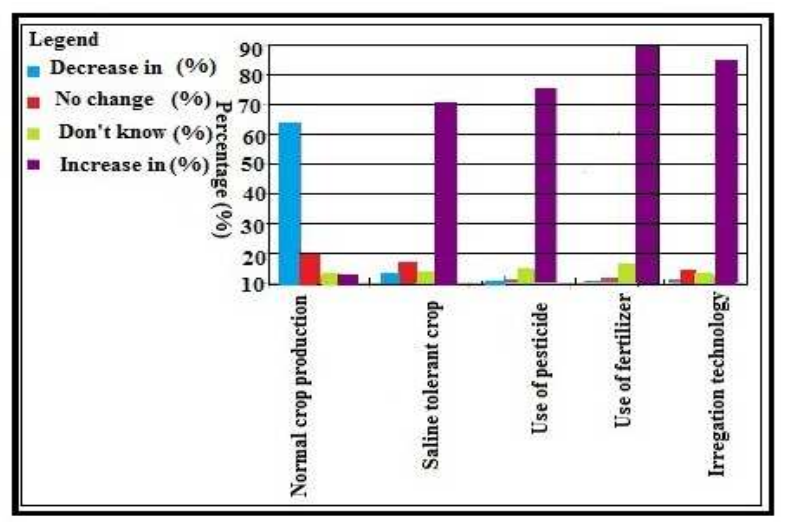

Fig 3. Local respondent perception (\%) on different agricultural activity in study area.

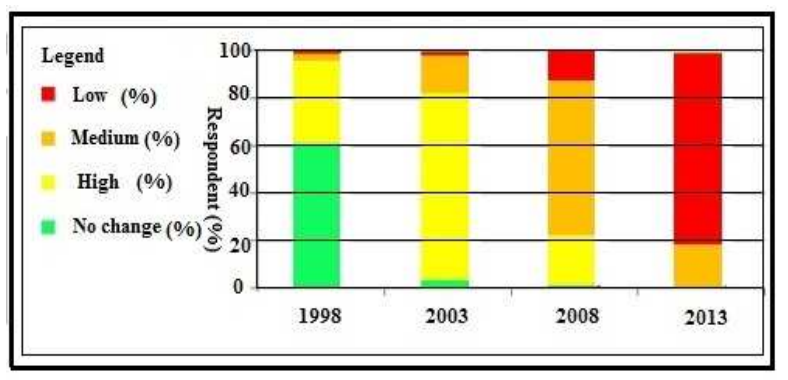

Fig 4. Local respondent perception (\%) on trend of food production during last 15 years in the study area.

\subsection{Knowledge Variability of Community People}

Climate change and its consequences affect the crop production as well as food production. Knowledge variability concept is an outcome of socio-economic profile [17]. Education plays a significant role in adapting climate change impact on food chain production in a community.
Results indicated that $70 \%, 80 \%, 90 \%, 92 \%$ and $96 \%$ respondents were knowledgeable about climate change and agriculture productivity for G-1 to G-5 respectively (Fig. 5).

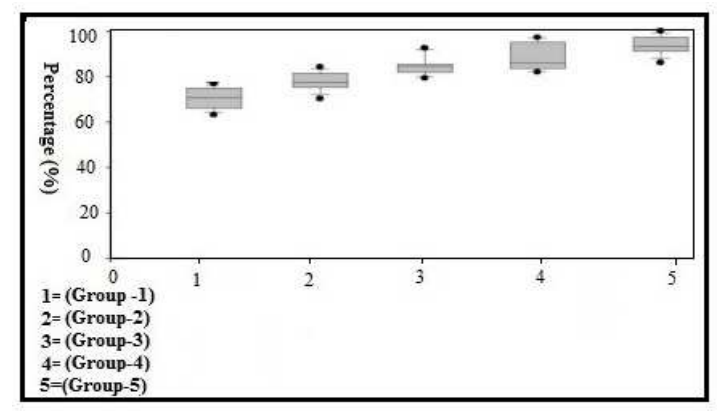

Fig 5. Knowledge variability on climate change and agriculture productivity in various groups.

\subsection{Correlation Coefficient Analysis}

Climate change and its effect have influenced social condition. Socio-economic condition with respect to climate change and food production have existed a correlation between them. Food production and climate change are matched with one another which provide a significant negative correlation was identified $(\mathrm{r}=-0.32 ; \mathrm{p}=0.01)$ for group one. A moderately negative correlation was observed to be climate change $(\mathrm{r}=-17 ; \mathrm{p}=0.01)$ and food security $(\mathrm{r}=-15 ; \mathrm{p}=0.01)$ for group two. Another low negative correlation was found to be food production $(\mathrm{r}=-10 ; \mathrm{p}=0.01)$ and income level $(\mathrm{r}=-08 ; \mathrm{p}=0.01)$ for group three. On the other hand, a significant positive correlation was found between climate change $(\mathrm{r}=30 ; \mathrm{p}=0.01)$ and education level $(\mathrm{r}=0.25 ; \mathrm{p}=0.01)$ for group four. Also similar moderately positive correlation were observed to be education level $(\mathrm{r}=18 ; \mathrm{p} 0.01)$ and food production $(\mathrm{r}=20 ; \mathrm{p}=0.01)$ for group five.

\section{Discussion}

Climate change has shocking impacts on food production in the coastal community of Bangladesh. Sea level rise have already threaten the coastal agricultural sectors, especially in low-lying coastal areas. South-western coastal region of Bangladesh have experienced due to effect of climate change by increasing temperature and erratic rainfall, flooding, salinity, erosion etc. Rosenzweing and Parry [18] estimated that net effect of climate change may lead to reduced global crop production up to $5 \%$. Socio-economic status of the respondent was governed by education level and occupational status with age group in the way of climate change impact in the community. Climate change impacts and its consequences, communities with educated populations are important in reducing the socioeconomic crisis (Table 1). These findings suggest that respondents from my study area about the changes in climate patterns as they provided different changes they believed are associated with changes in climate. More than $80 \%$ respondent was 
found that due to change in climate there is erratic rainfall, climate is getting warmer day by day due to increase in temperature, erosion, flooding incidents and natural disaster (Table 2). Kaul and Ram [19] found that excessive rains and extreme variation in temperature has adversely affected the crop productivity, thereby this has affected the incomes as well as food security of farming families in Karnataka, India. $85 \%$ of the respondents were agreed that increase in temperature and hence adversely affect in agriculture production. Increasing temperature will increase evaporation, soil and water temperature that enhance incidence of insect pest, disease and less fertile the agriculture lands [20]. The study confirms that people of the affected area experienced that salinity into land mass increased less fertile that causes failure of crop production [21]. Another study confirms that food production was decreased due to salinity and climate change [22]. Socio-economic factors affected in economy like age, sex, occupation, income level of the population; increasing demand of food grain product; rising price of food grains; low productivity of land, and low education level of farmers; and climate change and it variability [23].

In the study, majority of the respondents either strongly agreed or agreed due to climate change such as risk of crop failure, pest and disease, erosion, salinity, flood incidents and sea level are increased. On the other hand, most of the respondents either strongly disagreed or disagreed due to climate change such as food grain production, frequency of rainfall, deforestation, health status of people, fresh water availability are increased (Fig. 2). Similar result found in the coastal belt of southern part of Bangladesh that impact of climate change has significant decline in agriculture production [7]. Most of the respondent in the study area was educated which ensure knowledge adaptation power about climate change effect on food production. The majority of people are aware about global warming. So, it is significant that awareness buildup and adaptation strategies that make sure understand about climate change impact on future in the society (Fig. 3). Perception analysis revealed to assess the impact of climate change on food production. Focus group discussions and local respondents argued that food production decreased gradually over the last 15 years and especially over the past 5 years due to climate change impacts (Fig. 4). Correlation coefficient analysis was made a relationship between accurate information and knowledge variability in different category of group. High knowledge variability was presented where climate change and food production were highly concerned for group four and group five. From the perceived knowledge, it was recognized as decreased the food production as the effect of climate change in the study area (Fig. 5). There were many reason of climate change such as lack of awareness and knowledge about adapting climate change according to people perception [24]. So, it can be concluded that significant negative relationship is existed between food production and climate change. Correlation coefficient analysis indicates that adversely direct impact on food production due to climate change in the study area. Understanding the relationship between climate change and food production was one of the key thinking processes and activities which was carried out through correlation matrix analysis in the study area.

\section{Conclusion and Summary}

Coastal people are more vulnerable to climate change impact. In the study, it was observed that food security decrease day by day due to crop failure. Knowledge variability revealed that lowest level was observed in group one and two while highest level of variability was identified in group four and five. On the other hand, Correlation coefficient analysis indicated that significant negatively correlation was existed between climate change with food production for group one, two and three whereas significant positively correlation was observed with education, climate change and food production for group four and five. The people perceived assessment show that they aware of climate change and its consequence on food production. But lack of awareness and ignorance are major obstacle to cope with these climate changes. Most of the respondents perceived that food production was degraded in present time than past due to climate change and other causes.

The following adaptive measure should be taken for reducing climate change effect to cope with food insecurity

i) Awareness raising program should be built up to local people regarding food production issues.

ii) Indigenous knowledge and traditional adaptive technique apply to increase the crop production.

iii) Community based food storage capacity made to ensure food production in the study area.

iv) Government, NGOs and donor agency should collaborate to combat the climate change impact with respect to ensure food security.

v) Collaboration of traditional crop variety strategies and cropping pattern should be change to make sure food production.

vi) Community people encourage to obtaining green economy and used advance technology in agriculture sector.

vii) Further research and fund need for climate change should be accompanied vulnerable coastal people of the affected area.

viii) More tree plantation should be done around the coastal part of the Bangladesh.

\section{Acknowledgments}

We would like to thanks to the participants who have given valuable information about climate change and agriculture production for this study. Authors also acknowledge to Mr. Subaran Chandra Sarker, Lecturer, Dept. of Geography and Environmental Science, Begum Rokeya University, Rangpur, Bangladesh for his co-operation to prepare the location map of the study area. 


\section{References}

[1] M.T. Sikder, "The Impacts of Climate Change on the Coastal Belt of Bangladesh: An overview. Investigation of Risks \& Adapta tions on Agricultural Sector", Proc. of International Conference on Environmental Aspects of Bangladesh (ICEAB10), Japan, Sept. 2010. p. 26-28.

[2] J.A. Ahmad, Dastgir, and S. Haseen, "Impact of climate change on agriculture and food security in India", International Journal of Agricultural Environmental and Bio-technology, v.4 (2), pp.129-137, 2011.

[3] Food and Agriculture Organization of the United Nations (FAO), "Climate change and food security: a framework document", Rome (Italy), 2008.

[4] J. Schmidhuber, and F.N. Tubiello, "Global food security under climate change", Proceedings of the National Academy of Sciences of the United States of America, v.104 (50), p.581-596, 2007.

[5] M.A. Fahim, M.K. Hassanein, S.M. Abolmaty, A.A. Khalil and A.F. Abou Hadid, "Climate Change Adaptation Needs for Food Security in Egypt", Nat Sci. 2013; v.11 ( 12), pp. 68-74.

[6] A. Parvaiz, "Food Security in Great Peril from Climate Change", UN Conference on Climate Change in Copenhagen, 2009

[7] K.I. Amir, T. Ahmed, "Climate Change and Its Impact on Food Security in Bangladesh: A Case Study on Kalapara, Patuakhali, Bangladesh", J Earth Sci Clim Change v.4, pp. 155, 2013. (DOI:10.4172/2157-7617.1000155).

[8] M. Hollaender, 'Human right to adequate food: NGOs have to make the difference', CATALYST, Newsletter of Cyriac Elias Voluntary Association (CEVA) v. 8 (1), pp.5-6, 2010.

[9] B. Talukder, "Climate change and agriculture". Bangladesh Public Administration Training Centre (BPATC), Dhaka, 2007.

[10] T.N. Maraseni, J. Maroulis, G. Cockfield, "An analysis of Australia's carbon pollution reduction scheme". Int. J. Environ. Stud. vol. 66 (5), pp.591-603, 2009.

[11] W. Easterling, "Impacts, Adaptation and Vulnerability. Contribution of Working Group II to the Fourth Assessment Report of the Intergovernmental Panel on Climate Change (Cambridge Univ. Press, Cambridge, (2007), pp. 273-313.

[12] A. Kumar and P. Sharma, "Impact of Climate Variation on Agricultural Productivity and Food Security in Rural India".
Economics Discussion Papers, No 2013-43, Kiel Institute for the World Economy. http://www.economics-ejournal.org/economics/discussionpa pers/2013.

[13] BBS, "Compendium of Environment Statistics of Bangladesh 2010", Bangladesh Bureau of Statistics, Dhaka, Bangladesh, 2010.

[14] Berenson and D.M. Lavine, "Basic business statistics", $5^{\text {th }}$ edition, Prentice Hall publisher, 1992.

[15] A.L. Edwards, "Informal criteria for attitude statements. In: Techniques of attitude scale construction", New York, Appleton-century crofts, Inc., 1957.

[16] N. Vedwan, R.E. Rhoades, "Climate change in the western Himalayas of India: A study of local perceptions and response", Clim. Res. V.19, pp.109-117, 2001.

[17] M.A. Rakib, M.A.H. Bhuiyan, "Contamination: Food Toxicity and Local Perception", International Journal of Scientific Research in Environmental Sciences, v.2(1), pp.1-7, 2014 (doi.org/10.12983/ijsres-2014-p0001-0007)

[18] C. Rosenzweig, and K.C. Parry, "Potential impacts of climate change on world food supply", Nature, vol.367, pp: 133-138, 1994.

[19] S. Kaul, and G. Ram, "Impact of global warming on production of Jowar in India (special issue: sustainable agriculture in the context of climate change)", Agricultural Situation in India vol. 66 (5), pp.253-256, 2009.

[20] S. Bhadiwal, "Impact on agriculture-climate change and India, survey of environment"-The Hindu, 2007

[21] S.M.S. Mahmud, F. Najneem, K.S. Haque, S. Rahman, and M.M. Sharmin, "Climate change: A study on impact and people perception (A case study on Mongla upazila, Bagerhat District, Bangladesh)", Bangladesh Res. Pub. J. v. 4(2), pp. 153-164, 2012.

[22] T.A. Shovo, M.H. Howlader, and T. Kumar, "Risk and Vulnerability of Climate Change on Coastal People: A study form Socio-economic and Environmental Perspective. Bangladesh Res. Pub. J., v. 8(3), p.195-202, 2013.

[23] A. Shakeel, A. Jamal, and M.N. Zaidy, "A regional analysis of food security in Bundelkhand region Uttar Pradesh (India)", Journal of Geography and Regional Planning, v. 5 (9), pp.252-262, 2012.

[24] V.S. Rawat, "People Perception on Climate Change and Their Influence on Various Aspects around Tones Valley of Garhwal Himalaya", Environment and Ecology Research, v. 1(3), pp.150-154, 2013 (DOI: 10.13189/eer.2013.010305). 